\title{
Technologies for Knowledge Assimilation
}

Daniel E. O'Leary

Marshall School of Business, University of Southern California, Los Angeles, CA 90089-0441

oleary@usc.edu

\begin{abstract}
Assimilation is a critical issue for knowledge management. Knowledge may be gathered, created or converted, but if it is not assimilated, the organization will not be able to take action on that knowledge or actualize all of its potential value. As a result, unless knowledge is assimilated it will have limited use and impact on an organization. Accordingly, organizations are concerned with how to facilitate assimilation. This chapter provides an analysis of some key technologies for assimilation, focusing on knowledge storage, massaging, structuring, integration, filtering and navigation.
\end{abstract}

Keywords: Knowledge Assimilation, Knowledge Storage, Knowledge Massaging, Knowledge Structuring, Knowledge Integration (Knowledge Linking), Knowledge Filtering, Knowledge Navigation

\section{Introduction}

\subsection{Why is Assimilation Necessary in Knowledge Management?}

Researchers (e.g., O’Leary 1998b and O’Leary 1999) have argued that knowledge management requires a broad base of activities, including for example

- Conversion of data and text into knowledge

- Conversion of individual's and group's knowledge into accessible knowledge

- Connection of people and knowledge to other people and other knowledge

- Communication of information between users

- Collaboration between different groups, and

- Creation of new knowledge.

However, in order for the organization, and individuals within that organization, to fully leverage the knowledge, it needs to be assimilated. This can mean that the knowledge needs to be consistent with the existing knowledge or that new knowledge needs to be converted to a format consistent with previously existing knowledge.

- If new knowledge is not consistent with previous knowledge then that needs to be established and the implications of that finding need to be addressed. Perhaps the new knowledge will lead to whole new ways of doing things. However, in any case, in order for that to occur, there will need to be assimilation.

- Knowledge has to be assimilated into a format which can be used by the organization in its processes so that it "fits" into the organization's way of doing things. In this way, knowledge can be embedded into an organization's processes. If the knowledge calls for a new way of doing things then processes need to change, all of which can be part of the assimilation process.

If knowledge is not assimilated it may not be used or may be reused. In such a setting, the cost would be high, but the benefit low. As a result, organizations may question low return on investment or other metrics associated with the investment, limiting further investment in knowledge management. 


\subsection{This Chapter}

This chapter proceeds as follows. Section 2 defines assimilation and discusses the concept of assimilation in knowledge management. Section 3 examines how storage format (e.g., as documents or cases) provides a basis to facilitate knowledge assimilation. Section 4 investigates the setting where the knowledge is not stored as needed and so it must be massaged in order to meet user needs and be assimilated into the organization's knowledge. Section 5 studies how knowledge organization can facilitate assimilation, with particular focus on ontology solutions. Section 6 discusses how knowledge needs to be integrated with other existing knowledge to make assimilation possible. Section 7 examines manual filtering, computer supported filtering and using intelligent agents to do information filtering. Section 8 analyzes how technology can be used to facilitate knowledge navigation. Finally, section 9 provides a brief summary of the paper.

\section{Assimilation}

This section defines assimilation and relates it to a number of examples. In addition, this section briefly explores approaches to measure and facilitate assimilation.

\subsection{Definition}

A critical aspect of knowledge management is that of assimilation. Knowledge can be captured or created, but until it is assimilated it is not likely to receive extensive use. Random House Webster's Unabridged Dictionary 2001, gives a number of definitions of "assimilation," including the following

1. To take in and incorporate as one's own; absorb

2. To bring into conformity with the customs, attitudes, etc. of a group ....

3. To convert to substances ... suitable for incorporation ...

\subsubsection{To take in and incorporate as one's own; absorb}

From a knowledge management perspective, definition 1 focuses on the view of assimilation as taking raw knowledge or information in and embedding it within an organization's or individual's existing knowledge. This aspect of adding new knowledge requires that the knowledge be absorbed in conjunction with the previous knowledge.

Absorbing knowledge to take in as one's own may mean trying to make the new knowledge fit the existing knowledge. Alternatively, it could mean taking the existing knowledge and trying to make it fit the new knowledge. However, it is likely that the changing and fitting is somewhere in between those two extremes, with changing of both new and old knowledge.

As an example of the case where assimilation means making knowledge fit the existing knowledge, consider the ontologies developed by the professional services firms to categorize best practices knowledge. As seen in O'Leary (2000b) different firms in the same basic business chose different ontologies for even very specific knowledge management uses. In particular, in that study it was found that there were substantial basic differences between the categorization schemes for best practices knowledge bases developed by major firms. By building different ontologies, companies can meet their differential needs to organize knowledge so that it fits with their own existing knowledge and so that the knowledge can be absorbed into the organization. This example is discussed in greater detail below.

\subsubsection{To bring into conformity with the customs, attitudes, etc. of a group ...}

Knowledge is not pure and organizations need to make knowledge accessible by making it consistent with their context, including customs, attitudes etc. This view of assimilation focuses on making sure that knowledge fits in the organization. 
For example, the way that an organization introduces change can be critical to assimilation of knowledge (O'Leary 1999). As an example, Sviokla (1988) studied diffusion of knowledge management in the form of a system to support budgeting at Texas Instruments. At the time of the case study, Texas Instruments was organized into 8 major groups, including Defense Systems \& Electronics Group (DSEG). Each group consisted of entities. For example, DSEG had six entities, including the Business Development Entity. Each entity had about four divisions, e.g., the Business Development Entity included the Microwave Technology Products Division. Within divisions there were multiple departments, e.g., the Microwave Manufacturing Department. This basic organization structure is illustrated in figure 1.

\section{Texas Instruments Organization Structure}

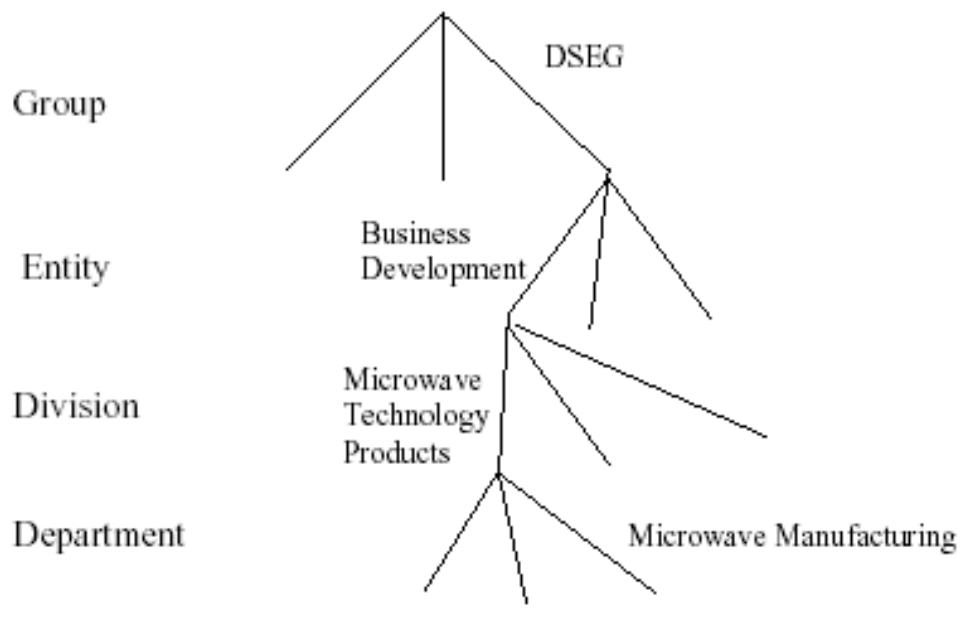

Figure 1

Unfortunately, the capital budgeting process had a number of limitations at the time. Capital expenditures required substantial documentation and committee review for any expenditure of $\$ 1,000$ or more. Larger expenditures could require up to four levels of management committees. DSEG prepared over 1,500 requests in a typical year, each of which could require substantial review time.

As a result, a knowledge management system, was built to facilitate the construction of proposals to be submitted for funding, as part of the capital budgeting process. The system was based on knowledge gathered at the Microwave Manufacturing department level and was designed to meet the needs of a rapidly growing department, with large capital requirements. Because the department had experience at generating (successful) capital packages, they had accumulated substantial expertise in knowing what the committees wanted to see in a capital proposal. The system had knowledge about depreciation, income taxes, and division production plans. A system user provided information about a particular capital proposal and then determined what would need to be done to make the proposal acceptable to the committee(s) responsible for evaluating capital proposals. For example, if the proposal included a request for a new welder, then the system would ask the user questions about when the welder would be needed and how many welds would be required. Based on past experience the system would determine if the welder would be approved based on the parameters gathered. Whereas, the rest of the company averaged an $80 \%$ success rate on their capital proposals, the Microwave Manufacturing Department was able to generate a higher acceptance rate. For one set of 50 proposals, the system indicated that three proposals would not be acceptable by the capital proposals group, whereas the other forty-seven would be acceptable. The system was right on all fifty. The system apparently was so successful at generating budget proposals, that other groups, entities, divisions and departments became interested in acquiring the system for their own use. Although this case raised many questions, assimilation of this system was facilitated by the extent to which the system leveraged knowledge about company policies and requirements. 


\subsubsection{To convert to substances ... suitable for incorporation ...}

Definition 3 suggests that the form to which the knowledge is converted is critical to the ability to use the knowledge. In that setting we may see organizations need to put the knowledge into particular formats e.g., rule-based vs. case-based, so that the knowledge is accessible in a manner consistent with the way that users are accustomed to accessing knowledge.

For example, as seen in O'Leary (2000a) management consultants used questionnaires to generate knowledge from their clients. For example, in order to determine if an organization was ready to engage in reengineering, a questionnaire with 20 questions was presented to the client. The client then assessed each of the questions with an integer ranging from 1 to 7 , with 7 indicating the highest level of readiness. Some sample questions included:

1. question(commitment 1$)=$ 'to what extent does the firm understand and share the case for action and vision of a major reengineering project $(1=$ no case for action or vision and $7=$ a strong case for action and substantial vision)?'

2. question(commitment 2$)=$ 'to what extent have senior managers been actively campaigning for the reengineering initiative $(1=$ no senior manager involvement and $7=$ extensive senior manager involvement)?'

3. question(commitment 3$)=$ 'to what extent does the organization attach urgency to the reengineering project $(1=$ no urgency and $7=$ extreme urgency $)$ ?'

The sum of the responses was then added together to generate a measure of how ready an organization was, seen in figure 1 . If all responses averaged a " 5 " or better then the company would be categorized as having a "High Level of Readiness."

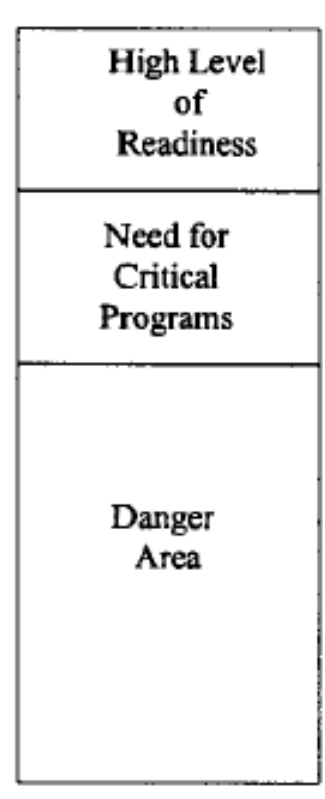

140

Figure 2 (Source: CSC Index, as cited in O'Leary 2000a)

Whereas in O'Leary and Watkins (1992), call center technicians used knowledge about specific client interactions stored as cases in a notebook and knowledge about modems as actual systems available for general review. Thus, in order to facilitate assimilation of knowledge for use in the first case, as compared 
to the second case, the knowledge is likely to require different storage formats. These examples and issues are discussed below in greater detail.

\subsection{How Can We Measure Assimilation?}

There are at least two (non-independent) approaches to understanding the extent to which knowledge has been assimilated: the extent it is embedded in the processes of an organization and the extent to which it is being used or reused.

\subsubsection{Embedded in Processes}

One approach to measuring the extent to which knowledge is assimilated is the extent to which such knowledge is embedded into an organization's processes. If knowledge is not embedded into processes then that suggests less assimilation than if knowledge was fully embedded in an organization's processes. For example, in a study of the professional services industry, O'Leary (2001) found that tax professionals appear to integrate substantial digitally available knowledge into their work processes. Information, such as tax legislation, rules, laws and legal case information are part of the knowledge management system and part of the information and knowledge that tax professionals use to do their job.

\subsubsection{Knowledge Use and Reuse}

Assimilation is critical to use and reuse of knowledge. Unassimilated knowledge will not be reused knowledge. Although there has been limited work in this area, O'Leary (2001) provided an investigation of knowledge reuse within periods and between time periods. Assimilation provides important motivation for reuse, since it is arguable if unassimilated knowledge will be used to begin with.

Frequently asked question (FAQ) files offer another view of the importance of use and reuse. A question asked of an expert can be posted along with its answer. A measure of the extent to which a FAQ file is assimilated is the extent to which FAQ files are accessed and reused.

\subsection{What Can be Done to Facilitate Assimilation?}

There are a number of approaches that can be done to facilitate assimilation. First, knowledge can be stored and fed back to users in a format that is consistent with the way that they expect to find the knowledge or one that fits unobtrusively into the process for which it is used. Second, knowledge can be massaged or compared to other knowledge, to help the user better understand that knowledge. Third, knowledge can be structured to facilitate search and organization of the knowledge. Typically, this is done using taxonomies or ontologies. Fourth, knowledge can be integrated with other knowledge (e.g., through linkages) in order to facilitate knowledge integration. Fifth, knowledge can be filtered to facilitate discovery of knowledge of interest to the organization. Sixth, knowledge can be navigated in a manner that facilitates assimilation. The remainder of the paper discusses each of these issues.

\section{Storage}

In order to facilitate assimilation, knowledge can be stored using a number of different conceptual models including the following (e.g., O'Leary 2000a, 2000b): documents, rules, cases, diagrams, Bayes' Nets diagrams and FAQ files.

\subsection{Documents}

A primary source of knowledge can be documents within an organization, such as letters, resumes, proposals, engagements and other sources. Documents are "naturally" occurring forms of knowledge deriving from existing processes. Systems such as Lotus Notes found their origin in efforts to capture information about documents generated from normal work processes. These systems typically have 
databases of documents. Within a database, the documents are likely to be similar. For example, there are so-called "proposal databases," that consist of a number of proposals. In addition, there are also databases of letters.

Associated with documents is additional information used to categorize the documents. That information can include originator, date, subject, etc. Such information can be entered with the document as part of the process or later discovered by intelligent agents.

\subsection{Rules}

A substantial amount of knowledge can be stored as rules for either human or computer-based consumption. For example, O'Leary (2000a) built a prototype system designed to facilitate the use of general rule-based knowledge about whether a firm was ready for reengineering. The system generalized a questionnaire used by CSC Index (1992) consultants to generate an index for reengineering readiness, as discussed above. As a result, the rules mirrored the way that work was done.

if $($ commitment $1=\mathrm{A})$ and $(\mathrm{A}=1$ or $\mathrm{A}=2)$ then commit1recommendation $=$ the firm needs to have a strong case for action and vision before proceeding with a reengineering project.

if $($ commitment $1=\mathrm{A})$ and $(\mathrm{A}=3$ or $\mathrm{A}=4$ or $\mathrm{A}=5)$ then commit1 recommendation $=$ it seems that there is a need for a stronger case for action and greater vision.

if $($ commitment $1=\mathrm{A})$ and $(\mathrm{A}=6$ or $\mathrm{A}=7)$ then commit 1 recommendation $=$ there is a strong case for action and the firm has a vision all necessary to make the project work.

Two other examples include Selfridge and Terveen (1996) system for business process support and reengineering and Nissen's (1997) system for reengineering support with measurement driven inference.

\subsection{Cases}

Case-based reasoning (CBR) sores knowledge at the case level (e.g., Kolodner 1988). O’Leary (2000b) found some evidence that CBR could be used to capture a range of knowledge for knowledge management, including knowledge about reengineering (Ku et al. 1996) and best practices (O’Leary 2000a).

As noted by Hammond (1987), CBR is based on the simple principle "if it worked, use it again," and "if it didn't work, then remember not to do it again." These basic concepts can guide the choice of cases available to an analyst to those that either worked or didn't work. For example, the call center, mentioned above (O'Leary and Watkins 1992), in order to accommodate the need for information about clients and particular situations employed case-based information to generate a history about the kinds of problems that have faced the client and the response of the client to proposed solutions. As another example Ku et al. (1996) built a case-based system for management of reengineering knowledge.

\subsection{Diagrams or Pictures}

Diagrams, also can be effective ways to store knowledge. Continuing the example of the call center technicians (O’Leary and Watkins 1992) where technicians were responsible for assisting customers determine communications hardware and software problems over the telephone. In this setting, technicians found that pictures of computers could be used unobtrusively to support the client interaction process. In some situations, clients would explain the physical structure of the equipment. If the analyst could not "picture" the configuration in their mind then they would go look at alternative physical computer configurations. Rather than have the analysts leave their posts, pictures of computers with the modems, along with explanations of the way they worked, were provided as part of the on-line knowledge management system. This had a number of advantages. First, call center technicians could more rapidly answer the customer's questions. Second, call center technicians did not need to disrupt the department by getting up and wandering around. Third, call center technicians could increase their available time by 
being available at their phones. Fourth, in the situation where the call center technician did not fully understand the way things worked, they could pursue additional support information on-line.

\subsection{Bayes' Net Diagrams}

O'Leary (2000a) presented a prototype system used to capture knowledge about what approach should be used for reengineering projects. Bayes' nets use Bayesian probabilities as a way of capturing the uncertainty associated with different sets of events. Bayes' nets embed those probabilities into a diagram that captures how things are causally related. Figure 3 provides one example of such a diagram. In the example, the primary issue is what is likely to be the domain in which reengineering is done, e.g., customer service, manufacturing or distribution. There are three sets of factors that influence the choice: Industry, location and method of analysis. The numbers derive from a study of reengineering developed by CSC Index (1994).

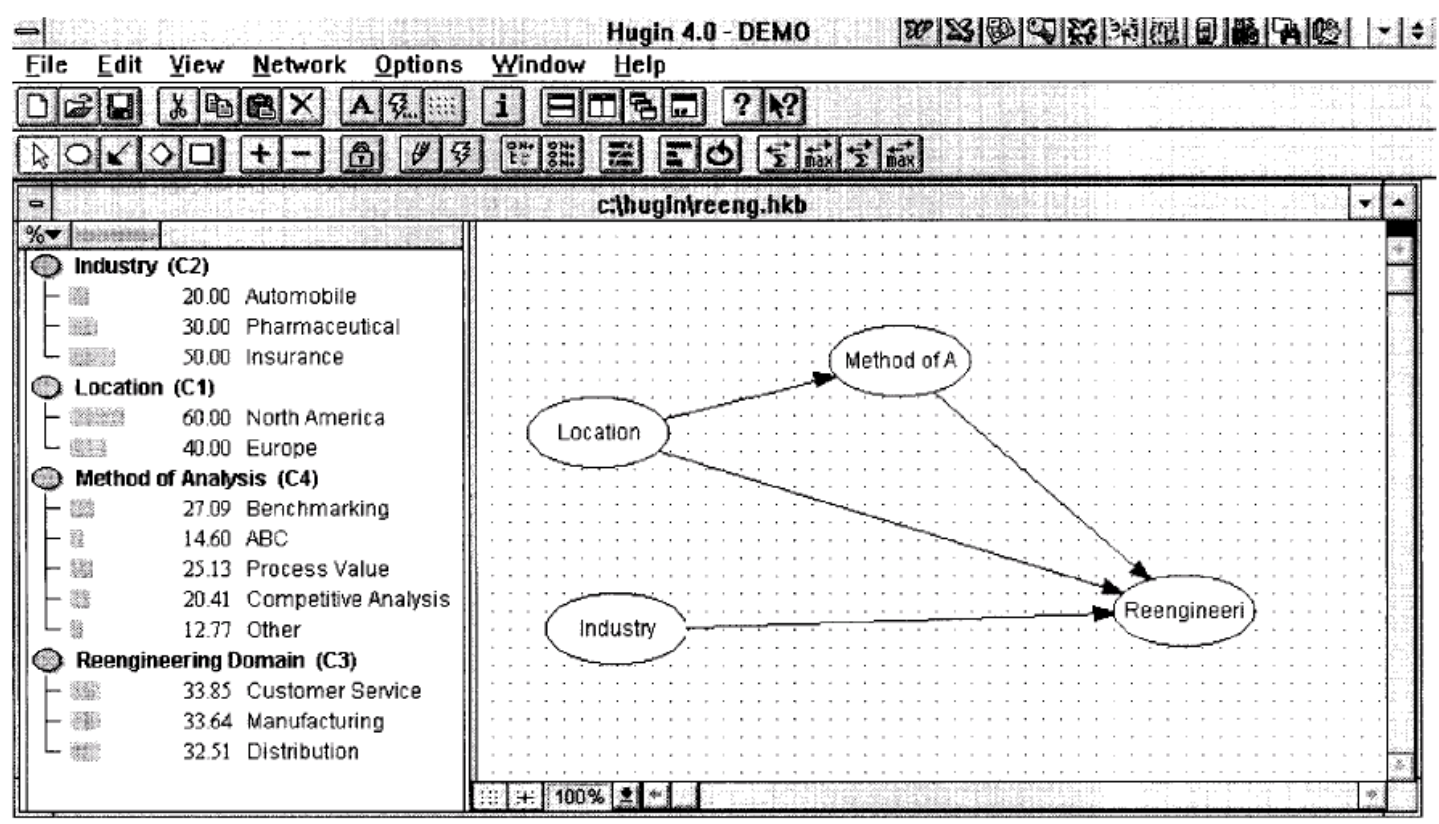

Figure 3 (Source O'Leary 2000a)

\subsection{Frequently Asked Question Files}

Another form of knowledge representation often affiliated with knowledge management systems is the frequently asked question (FAQ). FAQ files help assimilation of knowledge in a number of ways. First, FAQ files provide an answer to a question, facilitating knowledge assimilation. Second, the fact that a question is on a FAQ indicates that it has been asked before and so others have had the same question.

Knowing that others have asked a question, makes it clear that others also are using the knowledge. Third, FAQ files potentially get the knowledge out to a broader range of people then simply providing an answer to the person asking the question. With greater access comes the potential for broader assimilation.

\section{Massaging Knowledge}

An alternative to storing knowledge in a particular format is to generate an appropriate format. In the same sense that databases can provide multiple views of the same information, knowledge management systems can massage the knowledge to provide alternative structures. 
One approach is to use intelligent agents. Intelligent agents can facilitate assimilation by gathering additional data for comparative purposes or messaging the data into a format that users find appropriate. One example of agents was Price Waterhouse's "Edgarscan." Edgarscan was developed to take financial information from the U.S. Security and Exchange Commission's EDGAR database (Electronic Data Gathering and Retrieval System) in order to make the information available in an easier to use format, formerly on the web. Edgarscan periodically extracted data from EDGAR, storing the data in a data warehouse in a format appropriate for the users. In addition, based on profiles, users were informed about changes and updates to the data. Edgarscan's architecture is summarized in figure 4.

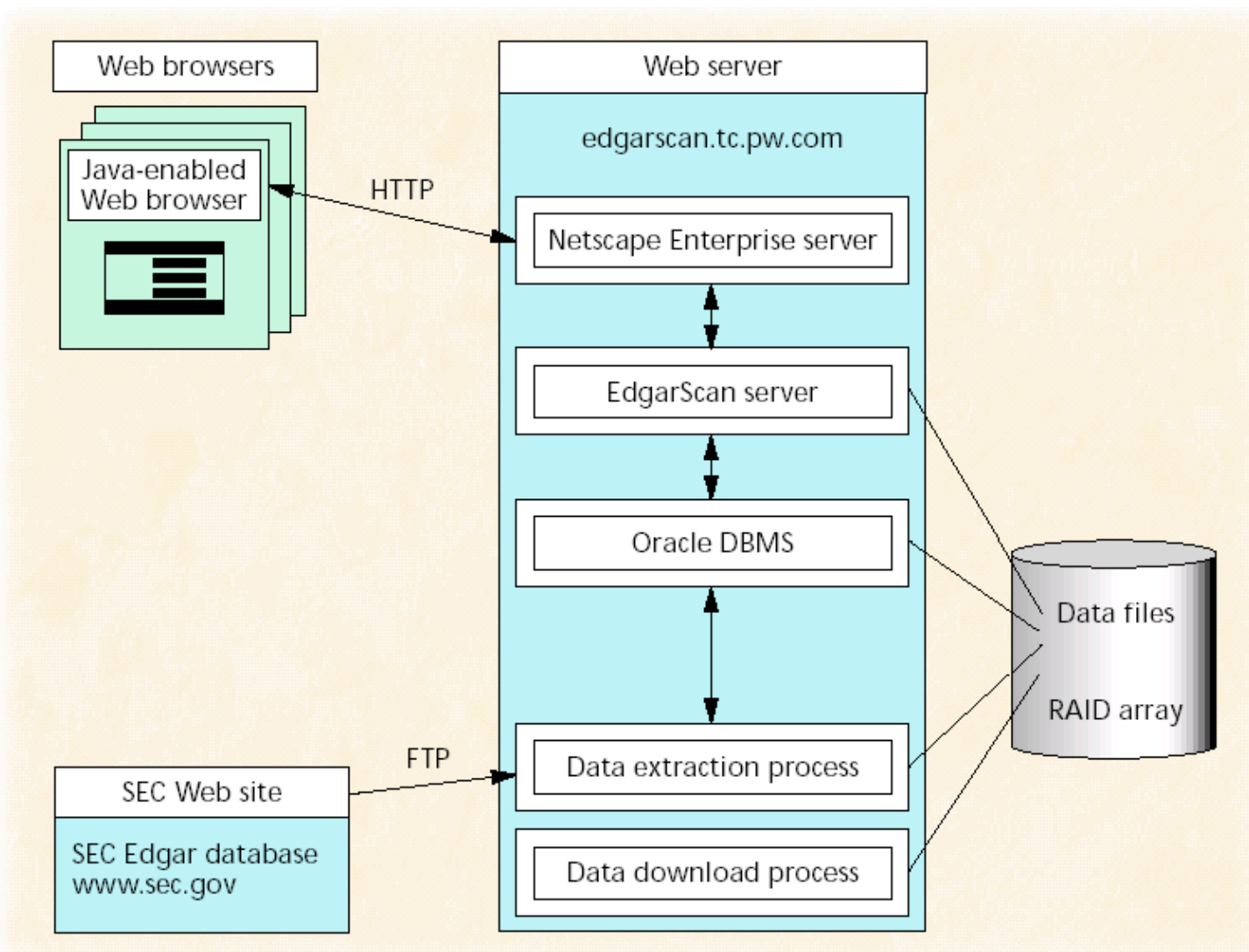

Figure 4-Architecture for Edgarscan (Cited in O’Leary 1998a)

With a set of data based on multiple companies, Edgarscan could also provide users benchmarking capabilities, with comparisons between different firms financial data (figure 5). Being able to provide benchmarking capabilities may be critical to assimilation since it helps integrate across existing knowledge. 


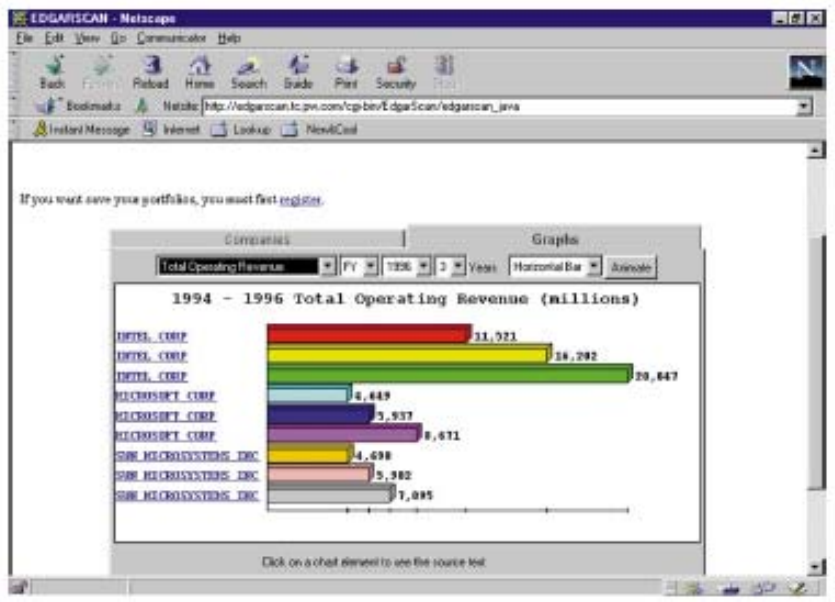

Figure 5 - Edgarscan Bench Marking Application (Cited in O’Leary 1998a)

\section{Organizing}

A key step to getting knowledge assimilated is that of organizing it. Organization of knowledge in the form of ontologies has been one of the key thrusts of knowledge management. As noted by Gruber (1993, p. 199), an ontology is an explicit specification of a conceptualization. Ontologies provide a way of organizing knowledge. At one level taxonomies provide an ontology.

\subsection{Human Generated Ontologies}

Researchers have found that apparently companies use ontologies as a means of facilitating assimilation of knowledge (e.g., O'Leary 1998c and 2000b). One area of the use of taxonomies/ontologies is that of "best practices." An example of two of the professional services firms' taxonomies for best practices, are provided in figures 6 and 7 .

Evidence of that need for assimilation is provided by the differences between best practices ontologies in different firms in spite of the similarity of the best practices in their knowledge bases. Although these ontologies are similar to each other and to Porter's (1985) value chain they differ along a number of different dimensions (O'Leary 2000b). For example, Arthur Andersen uses a category "Develop vision and strategy," but that category is not in either the Price Waterhouse version or Porter's version. Similarly, Porter uses "Inbound Logistics," and "Outbound Logistics," and Price Waterhouse uses "Manage Logistics," but logistics were not accounted for separately by Arthur Andersen's approach.

But ontology differences can be important. As noted by Price Waterhouse (Price Waterhouse 1995), "for the user the right (ontology) means the difference between spending hours looking for information or going right to the source." Assimilation is facilitated by the way that knowledge is organized. 


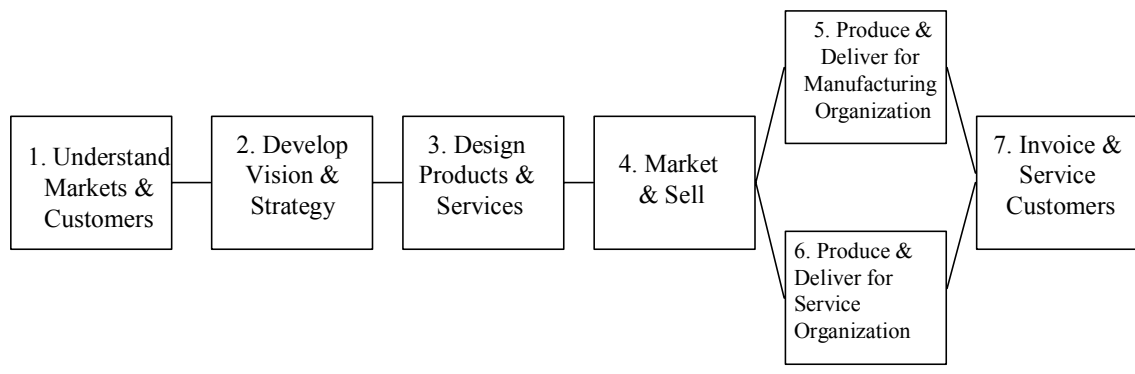

8. Develop and Manage Human Resources

9. Manage Information

10. Manage Financial and Physical Resources

11. Execute Environmental Management Program

12. Manage External Relationships

13. Manage Improvement and Change

\section{Global Best Practice Classification Scheme (Arthur Andersen)}

Figure 6

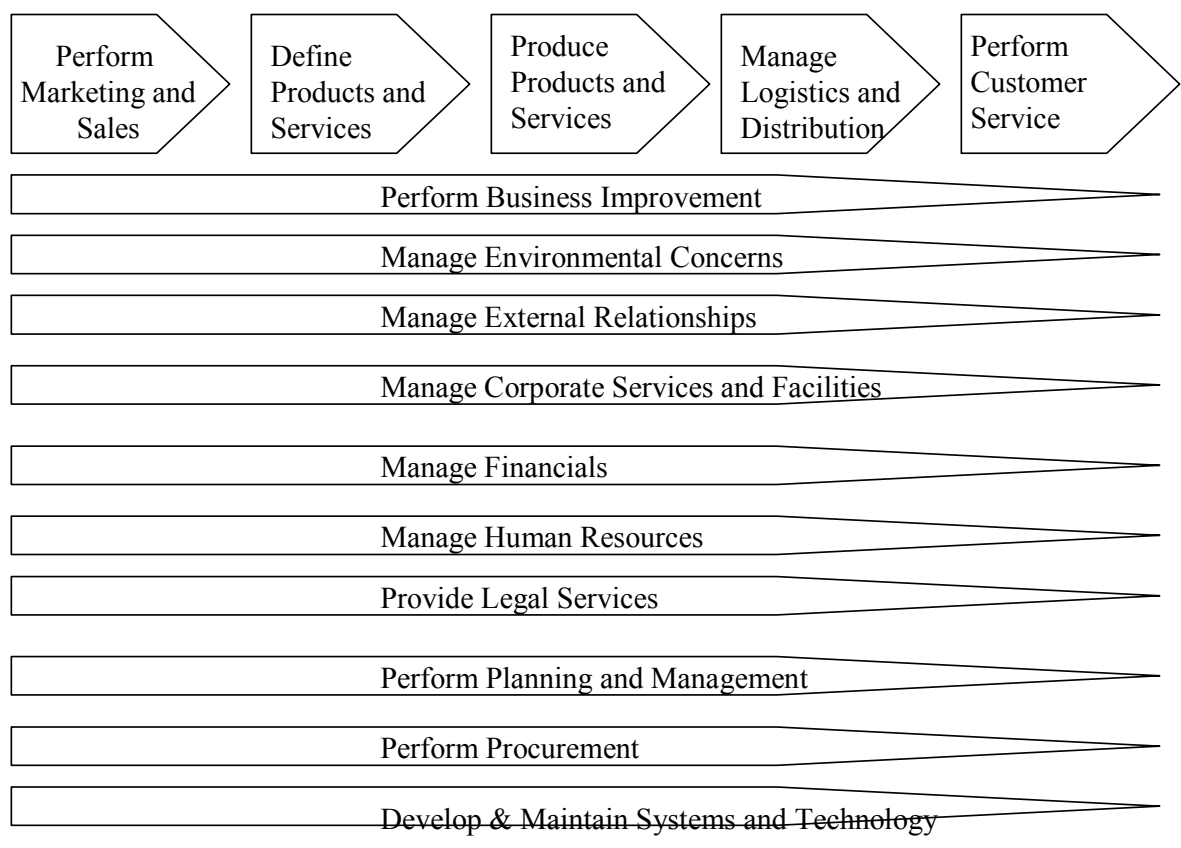

KnowledgeView Multi-Industry Process Technology (Price Waterhouse)

Figure 7 


\subsection{Intelligent Agents}

Although this discussion of organization has focused on structures generated by humans. Intelligent agent can be used as categorizers to automate the process of organization. However the resulting categorization of the knowledge does not have the depth associated with a human-generated ontology. In some situations, the resulting ontologies are referred to as "light" ontologies.

\section{Integration (Linking)}

Integration of knowledge into the firm's existing knowledge is critical to assimilation. Two approaches to such integration are linking knowledge to other knowledge and linking knowledge to people.

\subsection{Linking Knowledge to Knowledge}

One approach facilitate assimilation is to integrate the knowledge with other knowledge by linking knowledge. Choosing those integrative links is an important task. As noted by the business strategy director at Xerox (Elliot 1997), "Since many feel that the road to new knowledge is triggered by invalidating the old knowledge, tools that build these active connections and links between the new information and the old knowledge are really of high value."

In addition, assimilation is not the same for all users. As noted by Hildebrand (1997), "because all of the (Coopers \& Lybrand) ... employees don't look for the same information in the same way, (the system) is careful to offer several routes ... to each destination." Thus, it is important to be able to establish different links to the same knowledge.

\subsection{Linking Knowledge to People}

In terms of facilitating assimilation, linking knowledge to people may be even more important than linking knowledge to knowledge. If people have a question, ideally, they can go straight to the source.

Establishing links between knowledge and people has taken at least two different approaches: "who know who" knowledge bases and intelligent agents.

\subsection{1 "Who Knows Who or What" Knowledge Bases?}

A relatively traditional tool is to provide a knowledge base about who is familiar with what topics ("who knows what?" or "who knows who"). Given such a knowledge base, knowledge can be assimilated because of the ability to connect to the right person, for purposes of finding out from them information about a subject area or about people.

Although these kinds of knowledge bases can be very effective, there are some limitations of these databases that are often left out of discussions. First, these knowledge bases often ignore the time dimension. For example, when did the person know about a particular subject area. If there has been substantial time pass since their last work in the area then the knowledge of who knows what may not be relevant. Second, they often ignore the interest issue. Is the person still interested in the area. Part of a who knows what database should be "who is still interested?" Third, such systems often ignore the depth of knowledge. As a result, they are unable to answer questions such as what kind of tasks can the person do in a particular area. Fourth, "who knows what" knowledge bases are seldom linked directly to human resources systems. As a result, both systems must be updated independently. Accordingly, there are often discrepancies between the two systems.

\subsubsection{Intelligent Agents}

An alternative approach is to use intelligent agents to determine who knows who or what. One such system, "ContactFinder" (Kulwich and Burkey 1995) provided the ability to provide referrals based on information gathered from a consulting firm's world-wide bulletin board. Limiting intelligent agent search 
to recent time periods can help mitigate the time and interest problems of "Who knows what" knowledge bases.

\section{Filtering}

Knowledge filtering can be used to facilitate assimilation. Filtering tries to get the right knowledge to the right person at the right time. Filtering can be done manually, by people using computer-based approaches or with intelligent agents.

\subsection{Manual Filtering}

Historically, knowledge management has used people to filter knowledge into the system. For example as noted in Glasser (1999) at one time KPMG had 15 people gathering and filtering information for the KPMG knowledge management system. Similarly, at the National Security Agency, a nine member team determined if a "lesson learned" was valid (Payne 1996).

Unfortunately, there are some limitations of manual filtering. First, the process can be slow. Second, manual filtering potentially is quite costly, because of the large human actors necessary to perform the filtering.

\subsection{Filtering by People Using Computer-based Approaches}

There are a number of technologies available to facilitate filtering. One such approach discussed in O'Leary (1998a), is known as cascaded filtering. Individuals take responsibility for filtering information for others in the organization hierarchy. Information is filtered by categorizing for content and rating for importance. Within the organization, individuals provide the system with a profile of their interest. Then as information is encountered by individuals in the organization, it cascades its way through the organization.

Unfortunately, these technologies apparently have had trouble with acceptance. For example, in November 1997, Infoworld did a test of four systems designed to help with the filtering problem. Unfortunately, as of January 1, 2002, none of the four companies compared in that article (grapevine, KnowledgeX, Sovereign Hill or Wincite), still had functioning web pages (those given in the article).

\subsection{Intelligent Agents}

An alternative approach is to use intelligent agents to help users with content. King and O'Leary (1996) discussed how intelligent agents can be used to provide a new concept for executive information systems. For example, intelligent agents can filter messages, news information, information on the Internet or intranet and many other sources of information. In addition, O'Leary (1996) investigated how a number of intelligent agents can help monitor a broad base of knowledge bases.

\section{Knowledge Navigation}

Another issue of concern in the area of assimilation is knowledge navigation. The primary thrust in knowledge navigation for knowledge management has been an attempt to help the user "visualize" Internet or Intranet worlds. In particular, in order to facilitate assimilation, it is important to provide different approaches for assisting knowledge navigation. In this section we review hyperbolic browsing, table lens, and intelligent agents. 


\subsection{Hyperbolic Browsing}

Organizations are concerned with how the computer - human interface can facilitate knowledge assimilation by improving knowledge navigation. One tool is the hyperbolic browser, also known as the fish-eye display (figure 8).

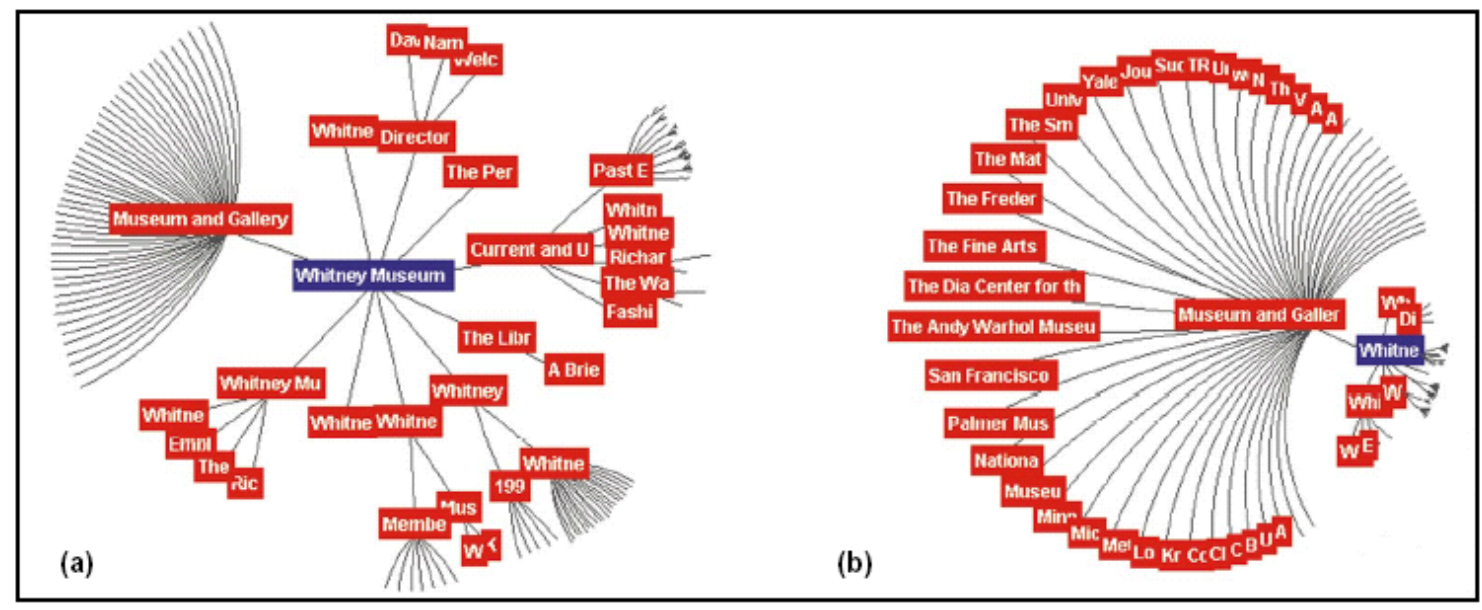

InXight's Hyperbolic Browser

Figure 8 (Cited in O'Leary 1998a)

Hyperbolic browsers exploit hyperbolic geometry in order to provide exponentially more information space for hierarchies that expand exponentially with depth. As a result, a hyperbolic browser might display 1000 nodes, whereas a conventional browser could display only 100. (See O'Leary 1998a and Lamping et al. 1995.) Users can navigate the space by clicking on a node to gain further detail and another view of the more detailed information. Inxight.com provides additional examples at http://www.inxight.com/products/vizserver/in_action_st.html.

\subsection{Table Lens}

Another approach designed to facilitate assimilation is known as the "Table Lens" (e.g., http://www.inxight.com/products/vizserver/tour tl_ 1.html). The table lens organizes data in a manner that it is hoped can facilitate discovery of patterns. Rather than using numbers, table lens employ relative comparison of a number of histograms or other visually oriented devices. For example, the table might be organized to present multiple columns of histograms of sales, with different offices listed across the top of the table and time periods listed down the side.

\subsection{Intelligent Agents}

Intelligent agents can play an important role assisting browsing to facilitate assimilation. For example, as summarized in O'Leary (1996) there are a number of intelligent agents designed to assist browsing, going back to Letizia and WebWatcher. In order to facilitate assimilation, those agents could be made bias to the knowledge desired to be assimilated into the organization. Rather than just choosing arbitrary available knowledge, the set of knowledge could be constrained or guided to specific knowledge.

\section{Summary}

Much of the previous research in knowledge management has ignored the issues associated with assimilation of knowledge into organizations. Just providing knowledge to potential users does not mean 
that it will be used. In particular, if knowledge is not assimilated that can inhibit its use. As a result, this paper has focused on the technology that can be used to facilitate assimilation into an organization.

The discussion of that technology was organized along six dimensions, including knowledge
- $\quad$ storage
- massaging
- organizing
- integrating
- filtering and
- navigating.

Each of massaging, organizing, organizing, integrating, filtering and navigating can be accomplished using substantial human effort, human effort supported by technology or intelligent agents, depending on the type and depth of analysis desired.

\section{References}

CSC Index, “Getting Started Form - Reengineering Readiness Scale,” 1992.

CSC Index, "State of Reengineering Report: North America and Europe," 1994.

Elliot, S. "APQC Conference Attendees Discover the Value and Enablers of a Successful KM Program," Knowledge Management in Practice, volume 5, January 1997.

Glasser, P., "The Knowledge Factor," January 1, 1999, http://www.cio.com/archives/010199/know_content.html

Guber, T., “A Translational Approach to Portable Ontologies,” Knowledge Acquisition, Volume 5, Number 2, 1993, pp. 199-220.

Hammond, K., “Case-Based Planning," in Kolodner (1988, pp. 17-20)

Hildebrand, C., "Face Facts,” Webmaster Magazine, February 1997, pp. 34-42.

Infoworld, Test Center Comparison: Knowledge Management Solutions,” Infoworld, November 17, 1997, Volume 19, Issue 46.

King, D., and O’Leary, D.E., “Intelligent Executive Information Systems,” IEEE Expert, December 1996, pp. $30-35$.

Kolodner, J., Proceedings of a Workshop on Case-Based Reasoning, Morgan Kaufman, USA, 1988

Kulwich, B. and Burkey, C., "ContactFinder: Extracting Indications of Expertise and Answering Questions with Referals," in Proceedings of the Fall Symposium on AI Applications in Knowledge Navigation and

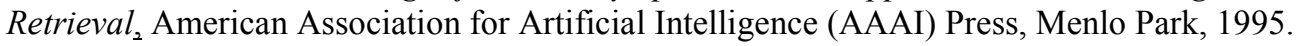

$\mathrm{Ku}$, S., Suh, Y. and Telcuci, G., "Building an Intelligent Business Process Reengineering System: A Casebased Approach," International Journal of Intelligent Systems in Accounting, Finance and Management, Volume 5, Number 1.

Lamping, J., Rao, R., and Pirolli, P., “A Focus + Content Technique Based on Hyperbolic Geometry for Visualizing Large Hierarchies," Proceedings of SIG CHI, ACM Press, New York, 1995. 
Nissen, M., “Reengineering Support through Measurement-Driven Inference," International Journal of Intelligent Systems in Accounting, Finance and Management, Volume 6, Number 2, June 1997, pp. 109120.

O’Leary, D.E., “AI and Navigation on the Internet and Intranets,” IEEE Expert, April 1996, pp. 8-10.

O’Leary, D.E., “Enterprise Knowledge Management,” IEEE Computer, March 1998a, pp. 54-61.

O’Leary, D.E., “Knowledge Management Systems: Converting and Connecting,” IEEE Intelligent Systems, May/June 1998b, pp. 30-33.

O’Leary, D.E., “Using AI in Knowledge Management: Knowledge Bases and Ontologies,” IEEE Intelligent Systems, May/June 1998c, pp. 34-39.

O'Leary, D.E., "Reengineering and Knowledge Management," in D. Fensel and R. Studer (eds) Lecture Notes in Computer Science, Springer, pp. 1-12, 1999.

O’Leary, D.E., "Management of Reengineering Knowledge: AI-Based Approaches,” International Journal of Intelligent Systems in Accounting, Finance and Management, Volume 9, pp. 107-118, 2000a.

O'Leary, D.E., "Different firms, different ontologies, and no one best

Ontology," IEEE Intelligent Systems (September/October), Vol 15(5) 2000b.

O’Leary, D.E., “How Knowledge Reuse Informs Effective System Design and Implementation,” IEEE Intelligent Systems, January/February, pp. 44-49, 2001.

O’Leary, D.E. and Watkins, P., "Integration of Intelligent Systems and Conventional Systems," International Journal of Intelligent Systems in Accounting, Finance and Management, Volume 1, Number 2, 1992, pp. 135-145.

O’Leary, D.E., and Selfridge, P. "Knowledge Management for Best Practices," Communications of the $A C M, 2000$, pp. 281-292.

Payne, L., "Making Knowledge Management Real at the National Security Agency," Knowledge Management in Practice, August/September 1996.

Porter, M., Competitive Advantage, Free Press, New York, 1985.

Price Waterhouse, “Welcome to Knowledge View," Price Waterhouse, 1995.

Selfreidge, P. and Terrveen, L., "Knowledge Management tools for Business Process Support and Reengineering," International Journal of Intelligent Systems in Accounting, Finance and Management, Volume 5, Number 1, March 1996, pp. 15-24.

Steier, D., Huffman, S. and Kadish, D., "Beyond Full Text Search: AI Technology to Support the Knowledge Cycle," AAAI Spring Symposium on Knowledge Mangement, AAAI Press, Menlo Park, California, 1997.

Sviokla, J., “Texas Instruments: Using Technology to Streamline the Budgeting Process," Harvard Business School, 1988. 